\title{
IMMEDIATE-FUNCTIONAL LOADING CONCEPT WITH ONE-PIECE IMPLANTS (BECES/BECES N/KOS/BOI) IN THE MANDIBLE AND MAXILLA- A MULTI-CENTER RETROSPECTIVE CLINICAL STUDY
}

\author{
Dobrinin Oleg1, Lazarov Alexander², Konstantinovic Vitomir S3, Sipic Olga ${ }^{4}$, Siljanovski Damir ${ }^{5}$, Milicic Biljana $^{6}$
}

1 Doctor, Senior Implantologist, Dobrinskaja Clinic, Krasnodar, Russia.

${ }^{2}$ Doctor, Member of the board, International Implant Foundation, Munich, Germany.

3 Faculty of Dentistry, Head of Maxillo-Facial Department, University of Belgrade, Belgrade, Serbia.

${ }^{4}$ Doctor, Intl. Implant Foundation, Department of Evidence and Research, Munich, Germany.

${ }^{5}$ Doctor, Intl. Implant Foundation, Department of Evidence and Research, Munich, Germany.

${ }^{6}$ Professor, Faculty of Dentistry, Department of Statistics, University of Belgrade, Serbia.

\section{BACKGROUND \\ ABSTRACT \\ Immediate functional loading is a hot topic in dental implantology. The use of conventional dental implants has proven to be successful for very few techniques and if enough jaw bone is present. In this study we report about the outcomes of treatments using the technology of the Strategic Implant $®$ in specialized clinics without any patient selection. \\ The purpose of this study was to evaluate the presently used protocol for immediate functional loading (within max. 3 days) of single piece implants which are placed according to the following principles- \\ - Axial implants with 2nd cortical anchorage (BECES®/BECES® N/BCS®), \\ - Lateral implants with dual mode of integration and cortical anchorage in horizontal direction (BOI@), \\ - Single piece compression screw implants (KOS/KOC) with conical endosseous implant body.}

\section{MATERIALS AND METHODS}

This retrospective cohort study included totally 394 patients who were treated with 4570 immediately loaded single piece implants (BECES ${ }^{\circledR}$ or BECES N®, BCS ${ }^{\circledR}$, BOI ${ }^{\circledR}$ BBBS/BAST and $\mathrm{KOC}^{\circledR}$, Strategic Implant ${ }^{\circledR}$, all obtained from Simpladent GmbH, Switzerland, Manufacturer: Dr. Ihde Dental AG) supporting fixed complete-arch maxillary or mandibular metal-acrylic prostheses, or metalceramic bridges or segment reconstructions in both jaws. Furthermore, 26 implants for single tooth replacement were inserted during the study period and $90(2.0 \%)$ single tooth on more than one implant reconstruction have been used, as shown in Table 1.

The patients were asked to return for follow up examinations at 6, 12, 18 and 24 months postoperatively. Radiographic assessment of:

- The marginal bone level,

- The integration of the load transmitting parts of the implants,

- The healing of sockets containing vertical implant parts,

were performed after at least 1 year in function for all patients.

Furthermore

- The reliability of possible target corticals

- The survival of bent and unbent implants, and the

- The survival of implants in fresh extraction sockets and healed bone

were determined.

\section{RESULTS}

Immediate functional loading of using multiple, cortically anchored Strategic Implant $₫$ as a support for fixed full-arch and segment prosthesis in the upper and lower jaw demonstrated a high cumulative implant survival rate (95.7\%) after an average observation period of $18.93+8.41$ months. The success rate of the individual implant depends on the target cortical in which it is anchored. Bent implants showed a better survival rate compared to non-bent implants, $98.5 \%$ vs $94.5 \%$, $(\mathrm{p}=0.003)$. Basal screw implant showed a similar survival rate as compressive screw implants. Combination implants (KOS plus) showed a significantly lower survival rate. BOI implant showed the highest possible survival rate, however the number of implants was low compared to other types observed in this study.

Clinical Significance- Immediate functional loading of single piece dental implants has become an accepted treatment modality for fixed restorations in totally edentulous mandibles and in edentulous maxillae. Nevertheless, studies regarding immediate loading procedures in extraction sites in both jaws, as well as in segment reconstructions and single teeth replacements, are limited. From the results of this study it can be concluded, that

The concept of treating edentulous "osseo-fixation" anchoring basal implants in the $2^{\text {nd }}$ cortical (instead of trying to achieve "osseo-integration" in the 1 st cortical and the underlying spongy bone) leads to a high success rate and allows functional immediate loading.

The results of the study are limited (although the sample size is enormous compared to other published studies in dental implantology) when it comes to determining if age, gender, smoking and generalized diseases or combinations thereof, and this is due to the very low complication rate of the treatment observed.

\section{CONCLUSION}

Within the limits of this study, it can be concluded that treatments with the technology of the Strategic Implant ${ }^{\circledR}$ give good results both in the edentulous and partly dentulous maxilla and mandible as well as for single tooth replacement. Furthermore, these 
implants may be placed into fresh extraction sockets almost with the same success as in healed bone. Bending of the implant necks rather increases the chances of survival for these implants. The survival of the individual implant depends on the chosen target cortical (2nd/3rd cortical) more than on anything else.

\section{KEY WORDS}

Metal-Acrylic Prosthesis, Bendable Implant Necks, BECES® Implant System, KOC@ Implant System, Complete Arch Reconstruction, Immediate Functional Loading, Retrospective Study, Tilted Implants.

HOW TO CITE THIS ARTICLE: Oleg D, Alexander L, Vitomir KS, et al. Immediate-functional loading concept with one-piece implants (BECES/BECES N /KOS/ BOI) in the mandible and maxilla- a multi-center retrospective clinical study. J. Evolution Med. Dent. Sci. 2019;8(05):306-315, DOI: $10.14260 /$ jemds/2019/67

\section{BACKGROUND}

Immediate/early implant loading procedures are well documented in cases of the edentulous mandible and the maxilla.1,2,3,4 Owing to lower bone density in the maxilla, immediate loading in the upper jaw is perceived as a greater challenge than in the mandible. Furthermore, the possibilities for implant placement in the totally edentulous maxilla is (For conventional 2-stage implants) often impossible due to bone resorption, which is especially frequent and pronounced in the posterior region of the maxillary arch. Therefore, bone grafting is according to traditional concepts often performed. The use of implant tilting in the maxilla has been demonstrated to be an alternative to bone grafting.5,6 By distal tilting of the distal implants in an arch, a more posterior implant- and abutment position can be reached in the "All-on-4-concept". At the same time, an improved implant anchorage can be achieved by using the cortical bone of the wall of the sinus and the nasal floor.

In our concept, however, we tilt the abutments of the distal implants in both jaws into mesial direction, utilizing the pterygoid plate of the sphenoid bone (In the upper jaw) and the lingual cortical undercut of the distal mandible are target $\left(2^{\text {nd }} / 3^{\text {rd }}\right)$ corticals.

Biomechanical analyses indicate that the most anterior and posterior implants supporting a reconstruction take the major load share at cantilever loading, irrespective of the number of intermediate implants7. For a given distance between the anterior and the posterior implant, the load supported by the most heavily loaded implant (The distal implant) is virtually independent of the total number of implants which support the restoration. These theoretic findings however, do not take into account changes in the periimplant mineralization in the postoperative phase, which is directed by the functional loading of every single implant. 8 Bending the necks of dental implants lead to internal stresses in the area of the implant shaft and the process of the inserted implants will impose enormous forces onto the bone. Assuming that all other parameters are equal, bendable (Basal) implants show a more even stress distribution along the vertical implant region than identically shaped implants with a machine-angulated area. implants, and even better than unbent implants which provide a thin region in the vertical implant area. ${ }^{9}$

'Financial or Other Competing Interest': None

Submission 16-11-2018, Peer Review 21-01-2019,

Acceptance 28-01-2019, Published 04-02-2019.

Corresponding Author:

Dr. Olga Sipic,

Dent32,

Desanka Maksimovic 4,

11000 Beograd, Serbia.

E-mail: oljasipic@gmail.com

DOI: $10.14260 /$ jemds/2019/67
Therefore, bendable basal implants probably resist masticatory forces better than pre-angulated, machined

The purpose of this study was also to evaluate retrospectively a treatment protocol in immediate functional loading for fixed complete-arch prostheses, segment reconstructions and single implants in the completely edentulous mandible and maxilla supported by cortically anchored implants and to evaluate implant success rate for those implants, where the abutment heads were parallelized through bending after implant placement.

\section{MATERIAL AND METHODS}

\section{Patient Characteristics}

In this study, we included 394 consecutively treated patients from out of whom 225 (57.1\%) were male, 169 (42.9\%) were female, with an average age: male $51.93+12.4$ and $51.74+11.59$ female, $20.8 \%$ suffering from hypertension, $4.6 \%$ diabetes and $27.6 \%$ smokers, who were treated in five different dental implant centers applying the technology of immediate functional loading with the Strategic Implant $₫$ (Table 1).

\begin{tabular}{|c|c|c|}
\hline \multicolumn{2}{|c|}{$\begin{array}{c}\text { Study Parameters } \\
\text { Parameters }\end{array}$} & $\begin{array}{c}\text { n (\%)/(X+SD; } \\
\text { (Med; Min-Max)) }\end{array}$ \\
\hline \multicolumn{2}{|c|}{ Number of Patients } & 394 \\
\hline \multicolumn{2}{|c|}{ Number of Implants } & 4570 \\
\hline \multicolumn{2}{|c|}{ Age } & $52.25+11.20(54.0 ; 22-79)$ \\
\hline Gender & Male/ Female & $169(42.9 \%) / 225(57.1 \%)$ \\
\hline Hypertension & Yes/No & $82(20.8 \%) / 312(79.2 \%)$ \\
\hline $\begin{array}{c}\text { Diabetes } \\
\text { Mellitus }\end{array}$ & Yes/No & $18(4.6 \%) / 376(95.4 \%)$ \\
\hline Smoker & Yes/No & $108(27.6 \%) / 284(72.4 \%)$ \\
\hline \multicolumn{2}{|c|}{ Table 1. Patient Characteristics } \\
\hline
\end{tabular}

\section{Implant Characteristics}

In this study we investigated different types of basal implants-

- Screwable basal implants (BECES®) 4095 (89.6\%),

- Compression screws (KOSß) 438 (9.6\%),

- Combination devices (KOS Plus®) 24 (0.5\%),

- Lateral basal implants (BOI®/ BBBS®) 13 (0.3\%)(Table 2).

\begin{tabular}{|c|c|c|}
\hline \multicolumn{2}{|c|}{ Implant Parameters } & n (\%) \\
\hline \multirow{4}{*}{ Type of Implants } & BECES/BECES N & $4095(89.6 \%)$ \\
\hline & \begin{tabular}{|l|} 
KOS \\
\end{tabular} & $438(9.6 \%)$ \\
\hline & KOS+ & $24(0.5 \%)$ \\
\hline & BOI+BBBS & $13(0.3 \%)$ \\
\hline Location of Implants & $\begin{array}{c}\text { Maxilla/ } \\
\text { Mandibula }\end{array}$ & $\begin{array}{c}2584(56.5 \%) / 1986 \\
(43.5 \%)\end{array}$ \\
\hline $\begin{array}{c}\text { Placed in Extraction } \\
\text { Sockets } \\
\end{array}$ & Yes/No & $\begin{array}{c}1642(35.9 \%) / 2927 \\
(64.1 \%)\end{array}$ \\
\hline Bent & Yes/No & $\begin{array}{c}2009(44.0 \%) / 2561 \\
(56.0 \%)\end{array}$ \\
\hline \multicolumn{3}{|c|}{ Table 2. Implant Characteristics } \\
\hline
\end{tabular}


All implants, which were used in this study, provided the possibility for bending in the neck area to align the direction of the insertion of prosthetics. The process of bending not only imposes stresses on the bone structures even up to the point where they might fracture, it also influences the mechanical properties of the implant material (and could lead immediately or later to fractures of the implant body). We have investigated furthermore the question, whether bent implants show lower, or higher, or identical clinical success to non-bent single piece BECES $®$ implants.

None of the clinics did any "patient selection" as it is done in the field of conventional dental implantology. No patient was rejected for "lack of bone substance", nor for any diseases that he carried. All centers excluded however patients who had reported earlier IV-Bisphosphonate treatment in their medical history. All other patients requesting treatment, received the treatment if the agreed to the treatment plan as set up by the Strategic Implantologist.

\section{Criteria of Success and Failure}

Criteria of possible failure were noted as follows: the existence of "discomfort", radiologically observable bone loss.

Criteria for survival and success were as follows: no pain, no mobility, no detectable infection, observed/reported bone loss visible in the panoramic picture with the survival of the implant not being endangered and the patient experiences no pain. This situation can be described as non-infectionassociated, function-derived modelling of the outer surfaces of the jaw bones, or simple post-extraction atrophy of the bone and soft tissues. All implants were placed in local anaesthesia and with the primary aim of anchoring the load transmitting apical (basal) threads in resorption free $2^{\text {nd }} / 3^{\text {rd }}$ corticals (for BECES $®$, KOS $®$, KOS plus $®)$, or horizontal bi-cortical support (for $\mathrm{BOI}{ }^{\circledR}$ ), regardless of the parallelity between the heads of the implants. KOC ${ }^{\circledR}$ compression screw implants were rigidly anchored through compression of trabecular bone areas and in the $1^{\text {st }}$ cortical. BOI $\AA$ implants were anchored horizontally between the outer and inner cortical of the jaw bone. The patients were asked to turn up for follow up examinations at 6, 12, 18 and 24 months. Not all patients appeared that regularly over the full observation period, however, if they did appear later on for control during the observation period, they were not left out from the study and their last control appointment became their date of last control. All patients who were enrolled into the study have reached at least the 12month control and were controlled clinically and through an $\mathrm{x}$ ray, which helped to assess:

- The marginal bone level,

- The integration of the load transmitting parts of the implants,

- The healing of sockets containing implants.

For all patients after at least 1 year in function.

\section{Technique and Treatment Protocol}

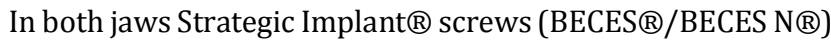
were used with the primary aim of cortical anchorage of the load transmitting thread at least in the $2^{\text {nd }} / 3^{\text {rd }}$ cortical. Many implants were inserted into fresh extraction sockets even in cases when profound periodontal involvement and or periapical osteolysis was present. As an alternative to basal screw implants, compression screw implants into the upper and lower jaw were inserted with the primary aim of achieving stability through compression of trabecular bone along the vertical (Endosseous) axis of the implant. Compression screws were inserted only into healed sockets. It was left fully to the decision of the surgeon, which implant type he/she would use in the individual patient and the individual bone site. All treatment providers had a sufficient stock of implants or all types on hand, allowing them to perform the optimum treatment variant to all patients. None of the treatment providers applied the technique of guided surgery nor used surgical guides. Some treatment providers used however in selected cases 3-D-planning with the primary aim of predetermining aesthetics.

All centers followed the same surgical and prosthetic strategy: all implants were splinted with a first fixed stable bridge (Circular or segmental) within max. 72 hours. Implants for the replacement of a single tooth were equipped either within the same period with a final fixed prosthesis or with a cemented fixed temporary one, and these were left out of occlusion. Segment bridges and full bridges were installed in full functional loading, and they were designed to allow equal bilateral mastication, following the concept which Ihde \& Ihde ${ }^{\mathbf{1 0}}$ had outlined.

All bridges consisted of a metal frame and veneering either from acryl, composite or ceramics. They were considered potentially permanent bridges. Replacements of bridges were not investigated in this study, however, if during bridge replacement also implants had to be replaced (e.g. due to vertical mobility), the lost implants were considered as failed. The new implant did not enter the study.

We followed a prosthetic concept for dental implants utilized in immediate loading protocols ${ }^{\mathbf{1 1}}$ where occlusal contacts were established on both premolars and the anterior half of the 1st molar but not distally to this area and not on the frontal group.

The position of the implants was characterized in two different ways:

- The point of penetration in the first cortical was noted intra-orally with the usual tooth positions, 11 - 48 in both jaws.

- The point of anchorage of the implant's thread in the 2nd/ 3rd cortical (target cortical) was chosen by the surgeon independently of the point of insertion into the 1st cortical, i.e. the implants were intentionally placed vertically or not vertically (tilted). In the upper jaw, three different anchorage regions were recorded: the floor of the nose for $1243(27.2 \%)$ implants, the floor of the sinus for $684(15.0 \%)$, the bone areas palatal to the maxillary sinus for $115(2.5 \%)$ and the pterygoid plate of the sphenoid bone for 549 (12\%). For example: an implant whose abutment head is positioned in the area of the upper canine could be anchored either in the floor of the nose or in the cortical floor of the maxillary sinus. By noting this detail, we were able to determine (though the success of the implants) which corticals were more reliable, Tables 3 and 4 .

Likewise, in the mandible inter-foraminal anchorage for 727 (15.9\%) and distal mandible anchorage without cortical engagement (i.e. with compression) for 389 (8.5\%) and with cortical anchorage for $863(18.9 \%)$, tables 3,4 and 6 .

\section{Methods - Statistical Analysis}

The time to event analysis provides a method to include implants who fail to complete the trial or do not reach study 
end-point (Censored data) by making comparisons between the numbers of survivors and success implants in each group at multiple points in time.

The Kaplan-Meier method can estimate the probability of surviving and success when implants have different lengths of follow-up. Implant survival and success rate were calculated from the start of treatment by the Kaplan-Meier method, and the differences between pairs of groups in survival and success were examined by the log-rank test. A p-value $<0.05$, from twosided tests, was considered statistically significant. Computation of data was done through SPSS program, ver 24. (Manufacturer: IBM Corp., Armonk, NY, USA)

Computation of data was done through SPSS program, ver 24. (Manufacturer: IBM Corp., Armonk, NY, USA)

\section{RESULTS}

\section{Patient Characteristics}

No patient was withdrawn from the study, and all 394 patients (with 4570 immediately loaded implants) were followed for at least 12 months. The longest control period was 57 months. If patients passed away during the observation period, their implants and constructions were counted as successful until the months during which they passed away (Table 6).

\begin{tabular}{|c|c|c|}
\hline $\begin{array}{c}\text { Type of } \\
\text { Follow Up }\end{array}$ & $\begin{array}{c}\text { Number of } \\
\text { Implants } \\
\mathbf{n}(\%)\end{array}$ & $\begin{array}{c}\text { Duration of } \\
\text { Follow Up } \\
\text { (X+SD; } \\
\text { (Med; Min-Max)) }\end{array}$ \\
\hline $\begin{array}{c}\text { Radiological Follow } \\
\text { Up }\end{array}$ & $4003(87.6 \%)$ & $\begin{array}{c}18.93+8.41 \\
(18 ; 0-49)\end{array}$ \\
\hline $\begin{array}{c}\text { Clinical Inspection as } \\
\text { Follow Up }\end{array}$ & $181(4.0 \%)$ & $\begin{array}{c}19.07+8.26 \\
(18 ; 0-49)\end{array}$ \\
\hline $\begin{array}{c}\text { Patient Report as } \\
\text { Follow Up }\end{array}$ & $386(8.4 \%)$ & $\begin{array}{c}20.04+9.17 \\
(18 ; 0-57)\end{array}$ \\
\hline \multicolumn{2}{|c|}{ Table 5. Patient Characteristics- Type of Follow Up } \\
\hline \multicolumn{2}{|c}{}
\end{tabular}

The average observation period for BECES $₫$ implants was $19.13+8.20$ months, and for KOS $囚$ implants was $19.03+8.10$ months.

Patients who missed a control appointment were kept in the study until their last appointment. If they turned up for control later on the observation of their case was prolonged. Hence, in our study we did not exclude patients who had missed one or several control appointments.

\section{Survival Rate of Implants and Success Rate of Prosthetic Work \\ Technical Complications}

No fractures or loosening of the cemented bridges were observed during the study. All prosthetic constructions (Even if they were planned for short- or medium-term temporary use) were cemented with Fuji Plus (Obtained from GC EUROPE N.V, Leuven) (Handmix variant) definitive cement. This procedure is necessary to establish absolute stability (Secure splinting) between the implants and the bridges as they are required according to the principles of therapy in traumatology and orthopaedic surgery (AO Principles).

\section{Comparison of Success Rate Regarding Prosthetic Work for all Implant Types}

There was no statistically significant correlation $(p=0.481)$ between full bridges (95.2\%) with segments (98.7\%) and single teeth restored with one implant $(100 \%)$ or single teeth restored with several implants $(100 \%)$. In case of pairwise comparison the results were not statistically significant (Fig. 1).

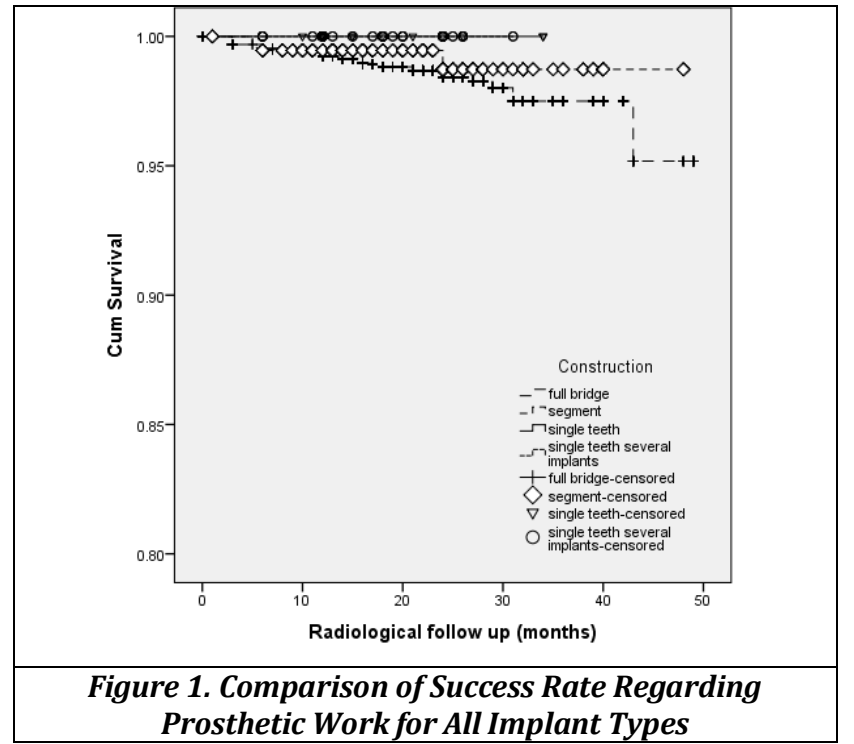

Comparison of Success Rate Regarding Prosthetic Work on BECES $®$ Implants

There was no statistically significant correlation between different types of prosthetic work on BECES $\AA$ implants $(p=0.962)$. In pairwise comparison the results were not statistically significant. Not one BECES® implant showed signs of peri-implantitis, neither clinically nor radiographically throughout the whole observation period (Fig. 2).

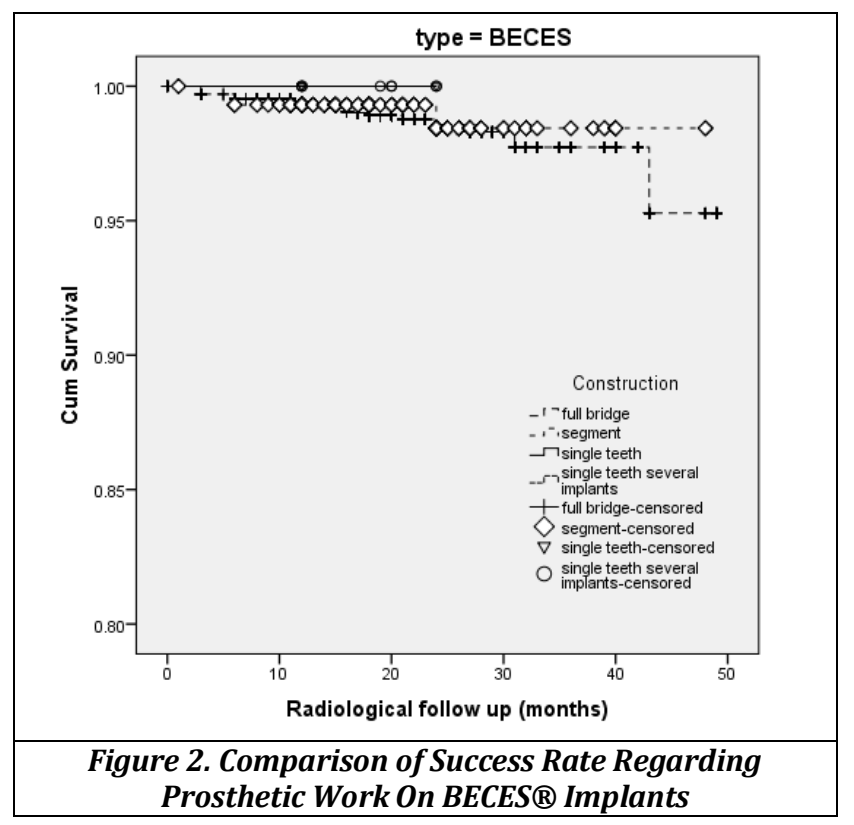

Comparison of Success Rate Regarding Prosthetic Work on $\mathrm{KOS} \circledast$ Implants

436 (99.5\%) KOS® implants out of 438 were in full function, without pain, mobility or visible infection, resulting in a clinical survival rate of $97.4 \%$ after a mean of $17.76+8.19$ months. 2 KOS® implants $(0.5 \%)$ showed radiographically signs of peri-implantitis with bone loss up to maximum $50 \%$ of the endosseous length (Table 9). 
There was no statistically significant correlation $(\mathrm{p}=0.504)$ between full bridges (95.8\%) with segments (100\%) and single teeth restored with one implant $(100 \%)$ or single teeth restored with several implants (100\%). In case of pairwise comparison the results were not statistically significant (Fig. 3).

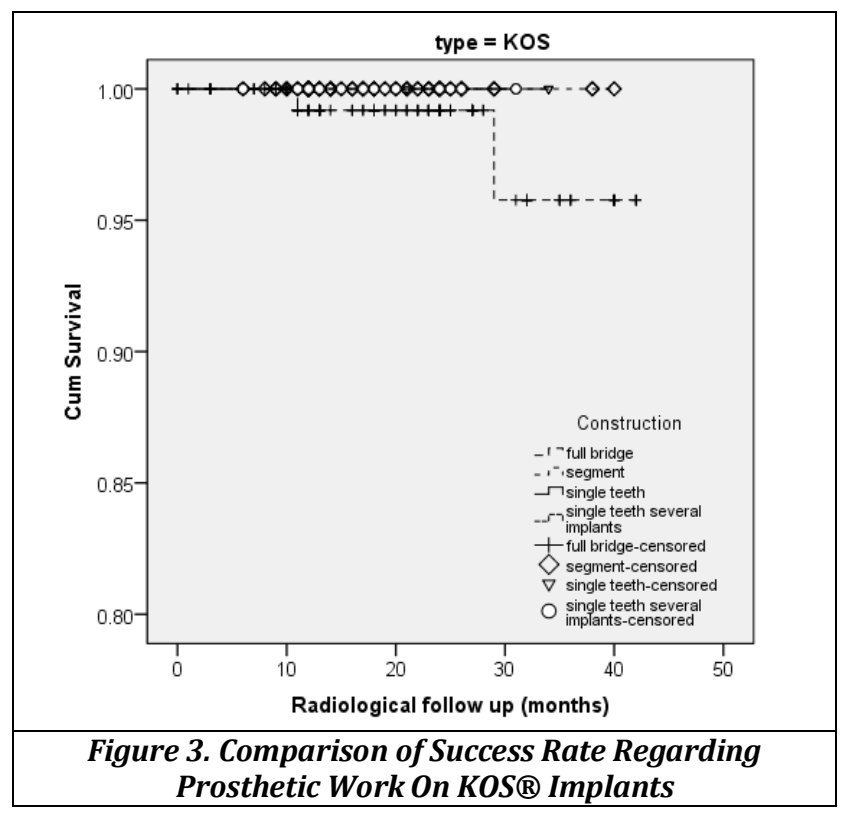

\section{Radiological Follow Up}

4003 implants $(87.6 \%)$ received a radiological control at the end of the individual observation period (Up to 57 months) in which: 181 implants (4.0\%) were inspected only clinically at the end of the individual observation period, because the treatment provider did not consider an x-ray necessary from the medical point of view. Nevertheless, these patients/implants should not be considered as drop out from the study since all patients at least answered to the questions of the clinic (Table 6). None of BECES implants showed radiological signs of peri-implantitis (Tables 9, 10,11).

\section{Survival Rate for All Implant Types}

The survival rate for all implant type placed in the mandible in comparison to those placed in maxilla was: $92.4 \%$ vs $98.5 \%$ (p=0.601) (Fig. 4)

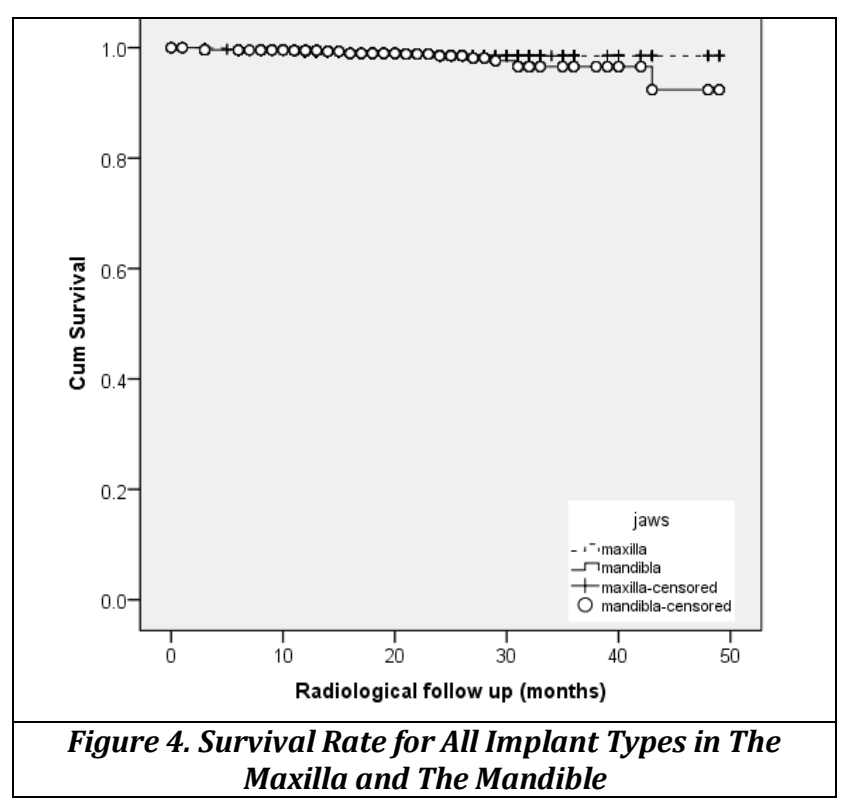

Survival Rate for BECES $₫ / B E C E S ~ N \circledast / B C S ®$ Implants $4048(98.9 \%)$ BECES $\AA / B E C E S$ N $® / B C S \circledast$ implants out of 4095 were in full function, without pain, mobility or visible infection, resulting in a clinical survival rate of $95.7 \%$ after a mean of 19+8.35 months. None of the BECES implants showed any sign of peri-implantitis (Table 6).

The survival rate for BECES implants placed in the mandible in comparison to those placed in maxilla came to: $92.1 \%$ vs $98.5 \%$ ( $p=0.803$ ). (Fig. 5)

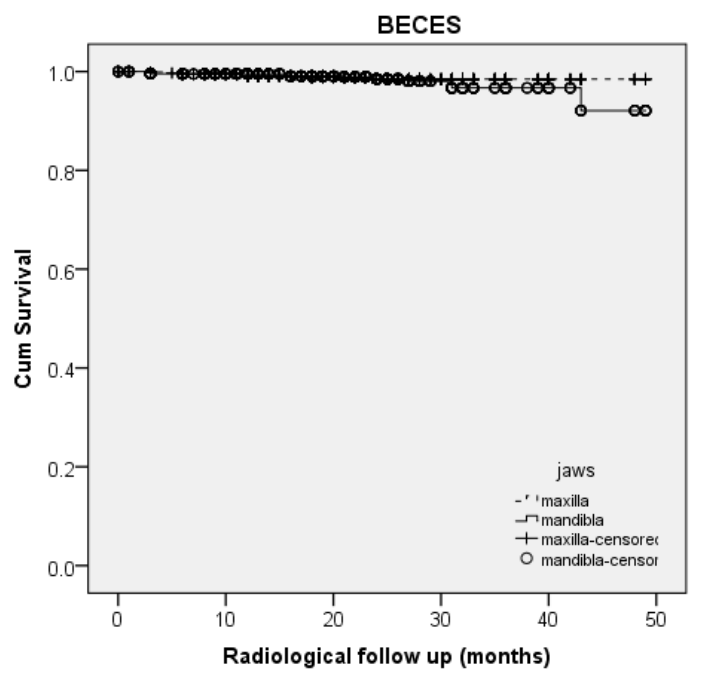

Figure 5. Survival Rate For BECES $® / B E C E S N \circledast / B C S ®$ Implants in Maxilla and Mandible

\section{Survival Rate of KOS Implants}

There was no statistically significant correlation in survival rate between $\operatorname{KOS} \AA$ placed in the mandible and maxilla, $\mathrm{p}=0.482$.

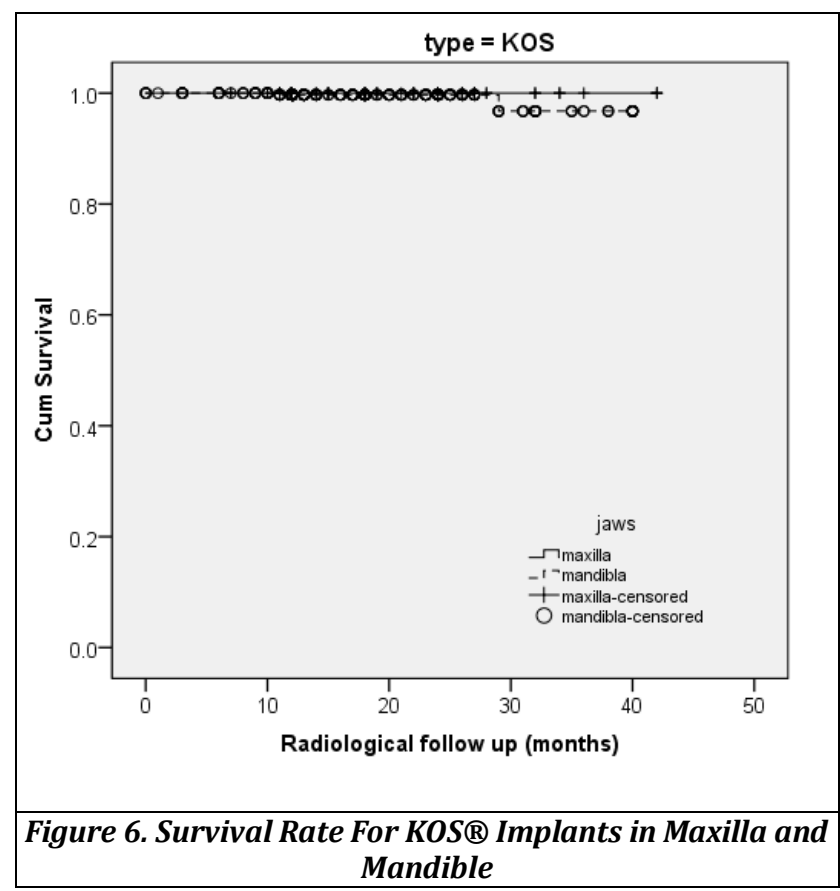

Survival Rate of BOI and BBBS Implants

$13(100 \%)$ BOI $\AA$ or BBBS $\AA$ implants out of 13 were in full function, without pain, mobility or visible infection, resulting 
in a clinical survival rate of $100 \%$ after a mean of $29.69+16.14$ months.

Survival of Implants in Different Sites of Placement

\begin{tabular}{|c|c|}
\hline Place of Anchorage in the 2nd Cortical & n (\%) \\
\hline Maxilla: Floor of Nose. & $1243(27.2 \%)$ \\
\hline Sinus Floor & $684(15.0 \%)$ \\
\hline Palatal & $115(2.5 \%)$ \\
\hline Tubero-Pterygoid & $549(12 \%)$ \\
\hline Anchorage & $727(15.9 \%)$ \\
\hline $\begin{array}{c}\text { Distal Mandible Anchorage Without Cortical } \\
\text { Engagement }\end{array}$ & $389(8.5 \%)$ \\
\hline $\begin{array}{c}\text { With Cortical Engagement in The Distal } \\
\text { Mandible }\end{array}$ & $863(18.9 \%)$ \\
\hline $\begin{array}{c}\text { Table 3. Analysis of the Frequency of the 2 } \\
\text { Cortical Used in Both Jaws }\end{array}$ \\
\hline \multirow{2}{\text{CTarget)}}{} \\
\hline
\end{tabular}

The surgeons were free to choose any of the reachable corticals. Table 4 will show later, the probability of implant survival is higher, if e.g. the floor of the nose is utilized, compared to the floor of the maxillary sinus.

\section{Implant Survival Under Different Aspects}

\begin{tabular}{|c|c|c|c|}
\hline $\begin{array}{l}\text { Place of Anchorage } \\
\text { in the } 2^{\text {nd }} \text { cortical } \\
\text { (Different Target } \\
\text { Corticals) }\end{array}$ & $\begin{array}{c}\text { Radiological } \\
\text { Follow Up }\end{array}$ & $\begin{array}{c}\text { Clinical } \\
\text { Inspection } \\
\text { as Follow up }\end{array}$ & \begin{tabular}{|} 
Patient \\
Report \\
as Follow \\
Up \\
\end{tabular} \\
\hline Floor of Nose & $99.2 \%$ & $99.2 \%$ & $99.3 \%$ \\
\hline $\begin{array}{l}\text { Palatal Engagement } \\
\text { (for anteriors and } \\
\text { premolars only) }\end{array}$ & $100 \%$ & $100 \%$ & $100 \%$ \\
\hline Tubero-pterygoid & 1010 & 010 & $99.1 \%$ \\
\hline $\begin{array}{c}\text { Mandible Inter- } \\
\text { Foraminal Anchorage }\end{array}$ & $99.2 \%$ & $99.2 \%$ & $99.2 \%$ \\
\hline $\begin{array}{c}\text { Distal Mandible } \\
\text { Anchorage Without } \\
\text { Cortical Engagement } \\
\text { (for KOS implants) }\end{array}$ & $88.7 \%$ & $94.6 \%$ & $88.8 \%$ \\
\hline $\begin{array}{l}\text { Cortical Engagement } \\
\text { Distal Mandible (for } \\
\text { BCS implants) }\end{array}$ & $89.4 \%$ & $89.2 \%$ & $94.4 \%$ \\
\hline Significance & $\mathrm{p}=0.000^{*}$ & $\mathrm{p}=0.001^{*}$ & $\mathrm{p}=0.001^{*}$ \\
\hline \multicolumn{4}{|c|}{$\begin{array}{l}\text { Table 4. Probability of Implant Survival at Different Place } \\
\text { of Implants Insertion }\end{array}$} \\
\hline \multicolumn{4}{|c|}{$\begin{array}{l}\text { *statistically significant; aLog Rank - comparison between } \\
\text { different places of insertion }\end{array}$} \\
\hline
\end{tabular}

Table 4 shows, that the survival of implants depends strongly on the target (2nd) cortical chosen. Best results for the maxilla were obtained if implants were anchored in the tubero-pterygoid region (Methods 10 and 10a), the floor of the nose (Methods 7a and 7b) or in palatal engagement (Method 11). Best results for the mandible were obtained if implants were anchored in the inter-foraminal region (Method 2 and 3) as well as in vestibular or lingual cortical engagement (Method 5a).

If teeth were extracted during the same appointment right before the implants were placed, it was noted that the placement was done into the sockets. Furthermore, we assessed radio-graphically during the 12 -month radiographic control appointment, if the sockets with the implants inside had filled with mineralized tissue, i.e. if the vertical bone growth along the implant took place so that the socket healed uneventfully more or less to the previous (pre-operative) bone level and mineralization.

\section{Complications}

Patients with 386 implants $(8.4 \%)$ were called by the staff of the clinics and the patient's report was noted. During this phone call the patients were interviewed regarding pain, discomfort and mobility of the construction. The reason for the interview was the fact that quite a few patients had (due to the big distance between the clinic and their place of living) no possibility to reach the clinics for the check-up. Tables 5 and 6 show complications as observed during clinical check-up and according to patients report.

\begin{tabular}{|c|c|c|c|c|}
\hline $\begin{array}{l}\text { Type of } \\
\text { Implants }\end{array}$ & $\begin{array}{l}\text { Mobility } \\
\text { No/Yes }\end{array}$ & $\begin{array}{l}\text { Radiological } \\
\text { Follow Up }\end{array}$ & \begin{tabular}{|} 
Clinical \\
Inspection \\
as Follow \\
Up
\end{tabular} & \begin{tabular}{|l|} 
Patient \\
Report \\
as \\
Follow \\
up \\
\end{tabular} \\
\hline BECES & $\begin{array}{c}4078 / 17 \\
(99.6 \% / 0.4 \%) \\
\end{array}$ & $\begin{array}{c}96.5 \% / \\
0 \%\end{array}$ & $\begin{array}{c}96.9 \% / \\
0 \%\end{array}$ & $\begin{array}{c}98.1 \% / \\
0 \%\end{array}$ \\
\hline \multicolumn{2}{|c|}{ Significance } & $\mathrm{p}=0.000^{*}$ & $\mathrm{p}=0.000^{*}$ & $\mathrm{p}=0.000^{*}$ \\
\hline KOS & $\begin{array}{c}438 / 0 \\
(100 \% / 0 \%)\end{array}$ & $97.4 \%$ & $97.4 \%$ & $97.7 \%$ \\
\hline \multicolumn{2}{|c|}{ Significance } & I & 1 & I \\
\hline KOS+ & $\begin{array}{c}24 \\
(100 \% / 0 \%)\end{array}$ & $83.9 \%$ & $83.1 \%$ & $83.9 \%$ \\
\hline \multicolumn{2}{|c|}{ Significance } & 1 & I & 1 \\
\hline $\mathrm{BOI}+\mathrm{BBBS}$ & $\begin{array}{c}13 \\
(100 \% / 0 \%) \\
\end{array}$ & $100 \%$ & $100 \%$ & $100 \%$ \\
\hline \multicolumn{2}{|c|}{ Significance } & 1 & / & / \\
\hline \multicolumn{5}{|c|}{$\begin{array}{l}\text { Table 5. Complications: Mobility and Survival and Success } \\
\text { Rate in Groups of Different Implants }\end{array}$} \\
\hline \multicolumn{5}{|c|}{$\begin{array}{l}\text { *statistically significant; aLog Rank -comparison between } \\
\text { implants with and without mobility }\end{array}$} \\
\hline
\end{tabular}

\begin{tabular}{|c|c|c|c|c|}
\hline $\begin{array}{l}\text { Type of } \\
\text { Implants }\end{array}$ & $\begin{array}{c}\text { Pain } \\
\text { No/Yes }\end{array}$ & $\begin{array}{l}\text { Radiological } \\
\text { Follow Up }\end{array}$ & $\begin{array}{c}\text { Clinical } \\
\text { Inspection } \\
\text { as Follow } \\
\text { Up }\end{array}$ & \begin{tabular}{|c|} 
Patient \\
Report \\
as \\
Follow \\
Up \\
\end{tabular} \\
\hline $\begin{array}{c}\text { BECES/ } \\
\text { Strategic } \\
\text { Implant }\end{array}$ & $\begin{array}{c}4087 / \\
8(99.8 \% / 0.2 \%)\end{array}$ & $\begin{array}{c}95.9 \% / \\
12.5 \%\end{array}$ & $\begin{array}{c}96.4 \% / \\
0 \%\end{array}$ & $\begin{array}{c}97.5 \% / \\
0 \%\end{array}$ \\
\hline \multicolumn{2}{|c|}{ Significance } & $\mathrm{p}=0.000^{*}$ & $\mathrm{p}=0.000^{*}$ & $\mathrm{p}=0.000^{*}$ \\
\hline KOS & $\begin{array}{c}435 / 3 \\
(99.3 \% / 0.7 \%)\end{array}$ & $\begin{array}{c}97.4 \% / \\
100 \%\end{array}$ & $\begin{array}{c}97.4 \% / \\
100 \%\end{array}$ & $\begin{array}{c}97.7 \% / \\
100 \%\end{array}$ \\
\hline \multicolumn{2}{|c|}{ Significance } & $\mathrm{p}=0.931$ & $\mathrm{p}=0.931$ & $\mathrm{p}=0.931$ \\
\hline $\mathrm{KOS}+$ & $\begin{array}{c}24 \\
(100 \% / 0 \%) \\
\end{array}$ & $83.9 \%$ & $83.1 \%$ & $83.9 \%$ \\
\hline \multicolumn{2}{|c|}{ Significance } & 1 & 1 & 1 \\
\hline $\mathrm{BOI}+\mathrm{BBBS}$ & $\begin{array}{c}13 \\
(100 \% / 0 \%) \\
\end{array}$ & $100 \%$ & $100 \%$ & $100 \%$ \\
\hline \multicolumn{2}{|c|}{ Significance } & 1 & 1 & 1 \\
\hline
\end{tabular}

Table 6. Complications: Pain, Survival and Success Rate in Groups of Different Implants and For Different Follow Up Methods

*statistically significant; aLog Rank - comparison between implants with and without pain 


\section{Implants: Failures and Remedies}

We observed that implant losses rather accumulated in specific patients. 11 patients, which amounts to $2.79 \%$ of the total number of patients, have lost 52 implants $-1.14 \%$ of the implants. This indicates that implant losses may be associated to case specific factors, such as overloading of implants, unilateral or anterior patterns of chewing and unequal mastication (Table 6).

\begin{tabular}{|c|c|c|}
\hline \multicolumn{2}{|c|}{ Observed Parameters } & n (\%) \\
\hline Mobility & Yes/No & $17(0.4 \%) / 4553(99.6 \%)$ \\
\hline $\begin{array}{l}\text { Local Soft } \\
\text { Tissue } \\
\text { Infection }\end{array}$ & Yes/No & $\begin{array}{c}6(0.1 \%) / 4564 \\
(99.9 \%)\end{array}$ \\
\hline Pain & Yes/No & $11(0.2 \%) / 4559(99.8 \%)$ \\
\hline \multirow{4}{*}{ Bone Loss } & No & $2908(63.8 \%)$ \\
\hline & $\begin{array}{l}\text { Natural Vertical } \\
\text { (atrophy) }\end{array}$ & $660(14.5 \%)$ \\
\hline & Crater Like & $3(0.1 \%)$ \\
\hline & $\begin{array}{c}\text { Retrograde } \\
\text { (from 2nd cortical) }\end{array}$ & $51(1.1 \%)$ \\
\hline Discomfort & Yes/No & $24(0.5 \%) / 4546(99.5 \%)$ \\
\hline \multicolumn{3}{|c|}{$\begin{array}{l}\text { Table 6. Implants: Failures and Remedies - Clinical and } \\
\text { Radiological Signs and Symptoms of Ailing or Failing } \\
\text { Implants }\end{array}$} \\
\hline
\end{tabular}

\section{Marginal Bone Level}

Readable radiographs were obtained from the patients at different time-points. At the end of the observation period for each case, i.e. on the last available radiograph image, the bone level was evaluated. Only one BCS $\AA$ implant, out of 4095 implants placed, showed radiological signs of crater-like bone loss during the observation. This could have been a sign of peri-implantitis. The clinical inspection of this case revealed however that the implant had been placed too close to the vestibular cortical, which then underwent modelling and vanished partly. Due to this process, a considerable part of the vertical implant shaft became situated outside of the alveolar bone, however this had not caused any infection because the implant was fully polished. Had the surgeon chosen a different method for insertion of these implants (e.g. method $7 \mathrm{~b}$ instead of method $7 \mathrm{a}$ ), this problem could have been presumably avoided. On the other hand, also extreme, unexpected bone resorption from the vestibular side may have caused this problem.

Around most of the implants which were placed into extraction sockets the vertical bone level had adjusted to the level anterior and posterior to that implant, which we consider a normal modelling after extraction, and not implant-related bone loss. All extraction sockets had filled with new bone uneventfully, almost up to the initial level. No difference in healing of the bone between sockets with and without implants was observed.

\section{Bending of the Implant Necks}

In order to allow non-parallel placement of single piece implants and to equip them with fixed cemented prosthetic constructions, the necks of these implants must be bent, unless the treatment provider decides to equip the implant heads them with angulation adapters. 2009 (44.0\%) bent implants vs. 2561 (56.0\%) were followed. The survival rate of bent vs. non-bent amounted to $98.3 \%$ vs $94.2 \%$, ( $p=0.043)$. Bent implants show better survival rates and the result is statistically significant (Table 2).

We assume that this results from the fact, that only those implants, which provide really stable anchorage in the $2^{\text {nd }}$ cortical can be bent, and the stability is tested during the process of bending. Unbent implants are however not tested for stability in the $2^{\text {nd }}$ cortical and therefore some of them may have failed to reach the $2^{\text {nd }}$ cortical.

\section{Prosthetic Constructions on Implants}

Implant survival was found to depend also on the prosthetic construction in which the implants were used, Table 6 and 7. Implants in upper jaw segments yielded a higher survival rate compared to lower jaw segments $(97.2 \%$ vs $100 \%$ survival, statistically significant differences $(\mathrm{p}=0.003))$, Implants in full lower bridges were less successful in lower jaw full bridges compared to upper jaw full bridges. Noteworthy is the high survival rate for immediately loaded single implants and constructions for the replacement of one tooth by more than one implant (e.g. replacement by one implant per lost root). Table 7 shows the comparison between the different prosthetic constructions in detail.

\begin{tabular}{|c|c|c|}
\hline Constructions & $\begin{array}{c}\text { Number of } \\
\text { Implants (\%) }\end{array}$ & $\begin{array}{c}\text { Radiological } \\
\text { Follow Up }\end{array}$ \\
\hline Full Bridge Upper & $2157(47.2 \%)$ & $98.7 \%$ \\
\hline Full Bridge Lower & $1365(29.9 \%)$ & $91.4 \%$ \\
\hline Segment Upper & $413(9.0 \%)$ & $97.2 \%$ \\
\hline Segment Lower & $516(11.3 \%)$ & $100 \%$ \\
\hline Single Teeth & $26(0.62 \%)$ & $100 \%$ \\
\hline $\begin{array}{c}\text { Single Teeth Replaced by } \\
\text { More Than One Implant }\end{array}$ & $90(2.0 \%)$ & $100 \%$ \\
\hline \multicolumn{2}{|c|}{ Table 6. Survival and Success Rate of Implants with } \\
Different Prosthetic Constructions
\end{tabular}

\begin{tabular}{|c|c|c|c|c|}
\hline \multirow{2}{*}{} & & $\begin{array}{c}\text { Full } \\
\text { Bridge } \\
\text { Upper }\end{array}$ & $\begin{array}{c}\text { Full } \\
\text { Bridge } \\
\text { Lower }\end{array}$ & $\begin{array}{c}\text { Segment } \\
\text { Upper }\end{array}$ \\
\cline { 2 - 5 } & Full Bridge Lower & $\mathrm{p}=0.044^{*}$ & & \\
\cline { 2 - 5 } & Segment Upper & $\mathrm{p}=0.175$ & $\mathrm{p}=0.930$ & \\
\cline { 2 - 5 } & Segment Lower & $\mathrm{p}=0.028^{*}$ & $\mathrm{p}=0.005^{*}$ & $\mathrm{p}=0.003^{*}$ \\
\cline { 2 - 5 } & Single Teeth & $\mathrm{p}=0.635$ & $\mathrm{p}=0.573$ & $\mathrm{p}=0.536$ \\
\cline { 2 - 5 } & $\begin{array}{c}\text { Single Teeth Replaced } \\
\text { by More Than One } \\
\text { Implant }\end{array}$ & $\mathrm{p}=0.359$ & $\mathrm{p}=0.273$ & $\mathrm{p}=0.218$ \\
\hline \multicolumn{4}{|c|}{$\begin{array}{c}\text { Table 7. Pairwise Comparison Survival and Success Rate } \\
\text { Between Different Prosthetic Constructions }\end{array}$} \\
\hline *statistically significant; aLog Rank - comparison between \\
implants with different prosthetic construction
\end{tabular}

\section{DISCUSSION}

\section{Implant Characteristics}

In previously published studies on (Cortically anchored) lateral basal implants, an immediate function concept for the edentulous mandible was presented with up to 11 years clinical follow-up. ${ }^{6,7,7,9,9]}$ Although the technology of lateral basal implants had proven to be successful even over such a long observation period, the technique never penetrated the market significantly. This is owed to strong opposition of traditional screw implant manufacturers and their protagonists at universities. Major screw implant manufacturers have constantly supported negative publication against cortically anchored, polished implants, because the success of these designs would question all claims 
regarding superiority of their specifically designed (Expensive) implant surfaces (e.g. SLA, Ti-Unite, etc.) in dental implantology. A group of practitioners has however over decades been working successfully on the concept described in this publication, which had already 20 years ago included an immediate functional loading protocol. The inclusion of BECES $®$ implants into immediate loading protocols (Since 2005), and the development and description of distinct methods of implant placement have led to the unique, powerful and reliable treatment concept as we describe it in this article. We also would like to mention here, that the concept of the "Bicortical Screw" which was introduced into our profession at the end of the 80s of the last century, was not sufficiently successful in the clinical reality, because at that time neither the distinct methods which we use today were known and defined, nor were at that time implants in a sufficient length available to reach and anchor into the tuberopterygoid region produced. Without the stable anchorage in the tubero-pterygoid region the technology described in this article cannot in all cases create sufficient support in the distal maxilla.

Although it would have been possible to deliver a fixed acrylic denture within a few hours, we preferred to deliver a rigid metal frame designed for acrylic or composite veneering. Hence, it could take up to 72 hours post-operatively until the bridges were ready for incorporation. The demand for a fixed, rigid splinting of non-parallel implants with multi-cortical anchorage stems from the field of traumatology 12 . Our treatment protocol resembles the procedures in that field, except that we utilize a custom-made splint (Bridge) which is inserted as soon as possible post-operatively, whereas in traumatology the devices to splint the fractures (And the implants) are prefabricated and fixed intra-operatively. Moreover, in the field of traumatology, specific implant surface characteristics (As deemed advantageous by leading dental implant manufacturers and their protagonists at the universities for decades) cannot play any role in immediate loading protocols. Bone does not heal nor integrates implant devices within 72 hours, nor does it build up mineralization in such a short period. Instead of waiting for "osseo-integration", both our Strategic Implant $\AA$ as well as the devices in traumatology and orthopaedic surgery are immediately "osseo-fixated" in resorption stable and highly mineralized cortical bone, a bone that provides almost no metabolism (And therefore enormous stability) and which by nature has a large potential for regeneration.

In the present study the mean bone level at the implant site did not change after up to 57 months of functional loading. This observation appears to be in accordance with the previous experience with a similar type of cortically anchored implants ${ }^{13}$.

High survival rates have been frequently reported in the literature for immediate function of fixed mandibular complete-arch prostheses supported by three or four implants, or on multiple basal implants ${ }^{14}$ however, when immediate loading is applied in the maxilla, a larger number of implants is generally used, although documented studies on delayed loading show equivalent outcomes when comparing the use of four or six maxillary implants as support for fixed full-arch prosthesis ${ }^{15}$. In traditional dental implant concepts practitioners faer the occurrence of "peri-implantitis". This disease, once it has started, melts bone away and leads to a significant decrease of the patient's quality of life. As our data shows, the dental implant technology used here does not lead to "peri-implantitis" and hence it seems allowed to use right from the beginning an appropriate amount of cortically anchored implants. This allows to work in an immediate load protocol and to create mulitcortical anchorage.

Our treatment concept uses the load-bearing capacity and the design of the jaw bones and adjacent bones in a favourable way. Owing to the freedom of tilting, the implant's thread can be anchored in dense bone structures (Especially in the lingual cortical of the distal mandible, the nasal floor, and the pterygoid plate of the sphenoid bone) and well spread anteriorly-posteriorly, giving an effective supporting polygon $^{\mathbf{1 6}}$ marked by four strategic positions, and with additional intermediate (Supporting) implants. Due to the thin, massive vertical implant parts $(2 \mathrm{mmD})$ and apical threads (mostly $3.6 \mathrm{mmD}$ ), each implant can be placed without coming into conflict with adjacent implants. To our knowledge, no published clinical studies have investigated immediate loading multiple screwable basal implants, fixated in the $2^{\text {nd }}$ and $3^{\text {rd }}$ cortical as support for fixed complete arch restorations in the maxilla. The concept of using highly mineralized bone which is far away from the location of the later teeth is best visible on tubero-pterygoid implants.

To accomplish immediate functional loading, a metalacrylic prosthesis was placed within a maximum three days after implant placement. The patients were informed preoperatively about the possible provisional nature of these bridges and that the eventual necessity to replace them later for various reasons might arise. The good clinical success rates may be owed to the fact, that never distal cantilevers had to be created, - neither in the upper, nor in the lower jaw. In the distal upper jaw tubero-pterygoid implants were placed to give distal support (Methods 10,10a), while in the distal lower jaw the lingual cortical was used for anchorage (Method 5a).

The clinical results of our work suggest that an accurately designed and supported metal-supported prosthesis serves well as a long-to-medium term provisional and may be successful, if used, even for a longer term, if aesthetics, phonetics and the flow of saliva are not negatively affected by small gaps which develop between the healed mucosa (supported by a modelled bone surface) and the bridge.

Malo et all have shown that their concept of "All on 4" implant in the upper and lower jaw provide reliable and good results. Our results are well comparable to the results on "All on 4" treatment modalities ${ }^{17}$. We prefer however to place implants both in the distal maxilla and the distal mandible and this allows us to cope with strong distal masticatory forces, to provide a full masticatory table from 6-6 in both jaws, and to reach this treatment aim even if the skeletal jaw relationship is unfavourable. No cases were excluded due to unfavourable jaw relationship (Angle Class II, Class III), although not always a "regular" overjet and overbite could be achieved as a result of the prosthetic treatment. Some patients received bilateral or anterior cross-bite. Many patients who showed an Angle Class 1 tooth relationship revealed their true Angle Class 2 skeletal jaw relationship at the end of the treatment. This indicates that both forced anterior bites and situations of "long centric" were treated successfully, and that the patients were given their prosthetics in true joint centric.

Since all the implants were placed in private dental centers, the average population profited from the treatment. 
All centers consequently treated all patients requesting treatment, which provided sufficient funds, accepted the comprehensive treatment plan, and had not received preoperatively any IV Bisphosphonate treatment. Hence no patient selection regarding the available bone supply nor any other pre-existing diseases or medications was done at all. In this respect our study differs significantly from all other know studies in dental implant dentistry. In general, all centers extracted all ailing or doubtful teeth, all wisdom teeth, all teeth blocking the way to reliable $2^{\text {nd }}$ or $3^{\text {rd }}$ cortical bone necessary to place a stable, cortically anchored construction for a potentially safe treatment plan. If patients did not have an adequate dentition (Masticatory surfaces) in the non-treated jaw, they were motivated to restore this jaw also (With or without implants). As a result of the treatment both jaws would provide at least 12 teeth (from 1 st molar of one side to the $1^{\text {st }}$ molar on the other side) with all premolars and the $1^{\text {st }}$ molar being in functional contact.

What is more, we would like to point out, that no patients were rejected from treatment due to "the lack of bone", nor were the centers performing "bone augmentations" nor "bone transplants" before or in combination with implant placement. All centers worked in all patient cases with the available amounts (Often only rests) of cortical bone.

The large number of patients and implants observed during the study period is another advantage of this study. Studies of this size are to our knowledge not available in the field of dental implants. We had to accept however that reallife patients skip control appointments more often and their compliance is questionable. Although patients tend to send their cars to inspections regularly, they do not take care as well when it comes to their teeth, and maybe this is why they are implant candidates at young age in the first place. We have to accept that many patients consider their former toothproblem as "solved" and that they do not wish to turn up for control appointments nor do they accept x-ray diagnosis unless there is a clear demand for this on their side. After 1-2 years, most patients trust that their treatment "works", many of them even forget that they have received implants and they considered their new teeth to be "their own".

The results of the study are however limited when it comes to determining if age, gender, smoking and generalized diseases or combinations thereof had influenced the successrate of implants and the cases in general. The problem which we encountered when doing the statistics was that although the total number of implants was very large, the failure- and complication rate was extremely low, and this did not allow to statistically determine the influence of the mentioned factors. Hence, we assume that IV-bisphosphonate treatment is the only (Time-limited and relative) contra-indication for treatments with implants in the oral cavity, and that the traditional contra-indications as considered for traditional 2 stage implantology do not apply. Today we consider the indications and contra-indications as a set up for orthopaedic surgery and in the trauma field, our valid borders for treatment. 18

\section{CONCLUSION}

Within the limits of the study, the following conclusions can be drawn-

1. Immediate functional loading using multiple, cortically anchored basal screw implants (BECES®), BECES
$\mathrm{N} \circledast / \mathrm{BCS} \circledast$ ) as well as when using KOC compression screw implants, as a support for fixed full-arch and segment prosthesis in the upper and lower jaw, demonstrated a high implant survival rate $(95.7 \%)$ after an average observation period of $18.93+8.41$ months.

2. The chance for survival of the individual implant depends on the location of $2^{\text {nd }}$ cortical anchorage, and the prosthetic construction to which it was connected.

3. When tilted posterior implants in the tubero-pterygoid where inserted, and the necks of the implants were subsequently bent, this did not affect the high survival rate and caused no clinically relevant damages to the bone. In fact, bent BECES $₫$ implants show a better survival rate compared to non-bent BECES $®$ implants $98.5 \%$ vs $94.5 \%, \quad(p=0.003)$, a statistically significant difference. We assume that the reason for this difference is that implants which have been bent, had thereby undergone a test for the stability of their cortical anchorage: If the anchorage was not proper, the surgeon had a chance to find out about this during the bending and he/she had the chance to improve the implant's position.

4. The chances for the survival of screw-able basal implants anchored in the $2^{\text {nd }}$ or $3^{\text {rd }}$ cortical does not depend on the presence of healed alveolar bone along the vertical shafts of the implants. If these implants are placed into fresh extraction sockets and anchored in the cortical beyond the corticals, they have a high success rate, however the survival rate in healed bone has been shown to be better in our study. The strategy and modalities of Strategic Implant placements into extraction sockets requires to be improved.

5. Although $1.1 \%$ of the implants had to be removed (with some of the prosthetic reconstructions being exchanged) all patients had reached and maintained their clinical treatment aim, with the remaining implants carrying successfully a fixed bridge. The clinical success rate of the immediate functional loading concept with cortically anchored implants or implants providing corticalisation (BECES $\AA / B E C E S N \AA, K O C \AA, C O I \circledast$ ) is $100 \%$. Removal of implants was in most cases done during routine replacements of first provisional bridges. If enough stable implants were left for holding the construction, no replacement implants were inserted.

The high cumulative implant survival rate indicates (within the limitations of this study) that the immediate functional loading concept with cortically anchored implants

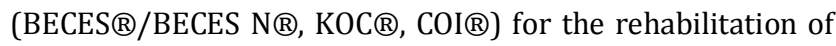
completely edentulous mandibles and maxillae as well as for segments and for single teeth replacement can be a viable concept even in cases where extractions of teeth were done simultaneously. To compare our survival rate to conventional 2-stage dental implant treatment is impossible, because in traditional dental implantology serious patient selection is state of the art and many of our cases (which we treated in an immediate loading protocol) would have required bone transplants or at least bone augmentations. It is known that these procedures are risky and tend to show failures, and if we would compare our technology to these procedures, we would have to take into consideration the various pre-implant remedies and their failures and complications also. 


\section{Manufacturer Name}

The medical devices used in this study were BECES, BECES N, BCS (GBC) (Screwable basal implants from the same manufacturer and with identical indication), BOI, and KOC (KOS) dental implants, manufactured by Dr. Ihde Dental AG for Simpladent $\mathrm{GmbH}$, both located at Dorfplatz 11, 8737 Gommiswald, Switzerland.

\section{REFERENCES}

[1] Tarnow DP, Emtiaz S, Classi A. Immediate loading of threaded implants at stage 1 surgery in edentulous arches: ten consecutive case reports with 1- to 5-year data. Int J Oral Maxillofac Implants 1997;12(3):319-24.

[2] Rocci A, Martignoni M, Gottlow J. Immediate loading in the maxilla using flapless surgery, implants placed in predetermined positions and prefabricated provisional restorations: a retrospective 3-year clinical study. Clin Implant Dent Relat Res 2003;5(Suppl 1):29-36.

[3] Olsson M, Urde G, Andersen JB, et al. Early loading of maxillary fixed cross-arch dental prostheses supported by six or eight oxidized titanium implants: results after 1 year of loading, case series. Clin Implant Dent Relat Res 2003;5(Suppl 1):81-7.

[4] Fischer K, Stenberg T. Early loading of ITI implants supporting a maxillary full-arch prosthesis: 1-year data of a prospective, randomized study. Int J Oral Maxillofac Implants 2004;19(3):374-81.

[5] Krekmanov L, Kahn M, Rangert B, et al. Tilting of posterior mandibular and maxillary implants of improved prosthesis support. Int J Oral Maxillofac Implants 2000;15(3):405-14.

[6] Aparicio C, Perales P, Rangert B. Tilted implants as an alternative to maxillary sinus grafting: a clinical, radiologic and periotest study. Clin Implant Dent Relat Res 2001;3(1):39-49.

[7] Rangert B, Jemt T, Jörneus L. Forces and moments on Brånemark implants. Int $\mathrm{J}$ Oral Maxillofac Implants 1989;4(3):241-7.

[8] Ihde S, Goldmann T, Himmlova L, et al. Implementation of contact definitions calculated by FEA to describe the healing process of basal implants. Biomedical Papers Med Fac Univ Palacky Olomouc Czech Repub 2008;152(1):169-73.
[9] Goldmann T, Ihde S, Kuzelka J, et al. Bendable vs. angulated dental implants: consideration of elastic and plastic material properties based on experimental implant material data and FEA. Biomedical Papers Med Fac Univ Palacky Olomouc Czech Repub 2008;152(2):309-16.

[10] Ihde S, Ihde AA. Cookbook mastication. $2^{\text {nd }}$ edn. Munich, Germany: International Implant Foundation Publishing 2015.

[11] Ihde S. Outcomes of immediately loaded full arch reconstructions on basal implants and teeth in the mandible: retrospective report on 115 consecutive cases during a period of up to 134 months. CMF Impl Dir 2008;3(1):50-60.

[12] Scortecci G. L'implantdentairetricortical. Thesis, Fac Odont de Marseille: 1988.

[13] Scortecci G. Immediate function of cortically anchored disk-design implants without bone augmentation in moderately to severely resorbed completely edentulous maxillae. J Oral Implantol 1999;25(2):70-9.

[14] Scortecci G, Misch CE, Benner K. Implants and restorative dentistry. London: Martin Dunitz Publication 2011.

[15] Ruedi TP, Murphy WM. Principles of fracture management. Stuttgart \& New York: Thieme Publishing Group 2001.

[16] Ihde S, Ihde A, Lysenko V, et al. New systematic terminology of cortical bone areals for osseo-fixated implants in strategic oral implantology. J J Anatomy 2016;1(2):7.

[17] Cooper LF, Rahman A, Moriarty J, et al. Immediate mandibular rehabilitation with endosseous implants: simultaneous extraction, implant placement and loading. Int J Oral Maxillofac Implants 2002;17(4):51725.

[18] Ihde S, Ihde AA. Diagnostics and treatment plan for the work with the strategic implant@. Munich: Intl Implant Foundation Publishing 2017 